\title{
LA MISOGINIA POPULAR COMO CONTRAMOVIMIENTO: ESTUDIO DE LA RESEMIOTIZACIÓN Y LOS DISCURSOS MANIPULATIVOS COMO DESAFÍOS CONTRA EL FEMINISMO
}

\section{Resumen}

El objetivo en este artículo es indagar en los procesos de construcción del discurso sobre el feminismo en España que articula la misógina popular. El análisis de tres casos de estudio nos permitirá revelar las estrategias discursivas que hacen posible el tránsito de un discurso multimodal a otro, así como la trasposición de significados adscritos al feminismo como movimiento social. La resemiotización, las categorías analíticas asociadas a los discursos manipulativos, el discurso especular y los conceptos de visibilidad y espectacularización constituyen las dimensiones metodológicas con las que abordamos la narración del feminismo que construye la misoginia popular. Finalmente, la discusión de los tres casos de estudio propuestos desvela un modelo específico de contramovimiento, asentado en marcos de producción de sentido vinculados a conceptos como la «ideología de género»o la «feminazi», que la misoginia popular ha opuesto al feminismo como movimiento crítico y a las demandas políticas ligadas a él.

Palabras clave: misoginia popular, resemiotización, manipulación, contramovimiento, «ideología de género», «feminazi»

\section{Resumo}

Misoginia popular como contramovimento: estudo da ressemiotização e dos discursos manipulativos como desafios contra o feminismo

O objetivo deste artigo é investigar os processos de construção do discurso sobre o feminismo que articula a misogenia popular, em Espanha. A análise de três estudos de caso permite revelar as estratégias discursivas que tornam possível o trânsito de um discurso multimodal para outro, bem como a transposição de significados atribuídos ao feminismo enquanto movimento social. A ressemiotização, as categorias analíticas associadas aos discursos manipulativos, o discurso especular e os conceitos de visibilidade e espetacularização constituem as dimensões metodológicas com as quais é abordada a narrativa do feminismo que constrói a misoginia popular. Finalmente, a discussão dos três estudos de caso propostos revela um modelo específico de contramovimento, baseado em quadros de produção de sentido vinculados a conceitos como «ideologia de género» ou «feminazi», que a misoginia popular opôs ao feminismo enquanto movimento crítico e às suas reivindicações políticas.

* $\quad$ Facultad de Ciencias de la Comunicación, Universidad Rey Juan Carlos, Madrid, España.

Dirección postal: Facultad de Ciencias de la Comunicación, Campus de Fuenlabrada, Despacho 118, Edificio Departamental I, 28943 Fuenlabrada (Madrid), España.

Correo electrónico: sonia.puente@urjc.es

ORCID: http://orcid.org/0000-0002-7246-5072

** Facultad de Ciencias de la Comunicación, Universidad Rey Juan Carlos, Madrid, España.

Correo electrónico: diana.fernandez.romero@urjc.es

ORCID: http://orcid.org/0000-0003-2692-4474 
Palavras-chave: misoginia popular, ressemiotização, manipulação, contramovimento, «ideologia de género», «feminazi»

\begin{abstract}
Popular Misogyny as a Countermovement: A Study of Resemiotization and Manipulative Discourses as Challenges Against Feminism

The goal of the article is to investigate the processes of the construction of discourses on feminism in Spain articulated through popular misogyny. The analysis of three case studies will allow us to reveal the discursive strategies that make possible the movement from one multimodal discourse to another, as well as the transposition of meanings attached to feminism as a social movement. Resemiotization, the analytical categories associated with manipulative discourses, specular discourse and the concepts of visibility and spectacularization constitute the methodological dimensions with which we approach the narrative of feminism constructed through popular misogyny. Finally, the discussion of the three proposed case studies reveals a specific model of countermovement based on frameworks of production of meaning linked to concepts such as «gender ideology» or the «feminazi», which popular misogyny has opposed to feminism as a critical movement as well as to the political demands linked to it.
\end{abstract}

Keywords: popular misogyny, resemiotization, manipulation, countermovement, «gender ideology», «feminazi»

\title{
Introducción
}

El 8 de marzo de 2019 el partido populista de ultraderecha Vox publica en su cuenta de Twitter ${ }^{1}$ un vídeo en el que se recoge la protesta de un grupo de mujeres feministas en la puerta de su sede. El vídeo se da a conocer con el título de «Feminazis visitan Vox» y lo acompaña el siguiente texto: «Gracias por vuestra loca visita, nos lo hemos pasado muy bien.» ${ }^{2}$ Con el titular «La musa de Vox contra las 'feminazis'» el diario El Mundo publica una entrevista de perfil a Rocío Monasterio, diputada de Vox en la Asamblea de Madrid, acompañada de una imagen de Monasterio reinterpretando el cartel de «Rosie, la remachadora» ${ }^{3}$ (Negre 2019). En febrero de 2018, la asociación ultracatólica Hazte Oír hizo circular en Madrid un

\footnotetext{
<https://twitter.com/vox_es/status/1104012430575845377>.

Ver canal de Youtube de Vox, em <https://www.youtube.com/watch?v=ZNsFc5Ne9CQ>.

El icono de Rosie, la Remachadora, Rosie the Riveter en el inglés original, responde al propósito de representar a las mujeres que trabajaban en las fábricas estadounidenses en el contexto de la Segunda Guerra Mundial. Su idea era reforzar su contribución en las fábricas de armamentos y suministros. La imagen que más se popularizó de este icono fue la encargada por la compañía Westinhouse Electric al creativo J. Howard Miller, en 1943, en la que aparece la imagen de una mujer ataviada con un mono azul, un pañuelo rojo con lunares blancos en la cabeza y un brazo doblado terminado en puño y mostrando músculo junto al lema «We can do it!». Esa semiotización original se ha resemiotizado en numerosas ocasiones tanto por el feminismo como por parte de la cultura pop o en la política, como en la campaña de presidencial de EE.UU. de 2008 por parte de Obama a través del lema «Yes, we can».
} 
autobús en cuyo lateral aparecía la frase «No es violencia de género, es violencia doméstica» junto a una imagen de Hitler con el hashtag \#StopFeminazis (Europa Press 2019). Estas tres narraciones multimodales dan cuenta de los mecanismos de construcción discursiva de la misoginia popular como contramovimiento focalizado en el desafío de las demandas sociales, legislativas y políticas del movimiento feminista. Precisamente en el momento en que el feminismo como discurso crítico se ha enmarcado con notable éxito en la esfera pública, emerge con fuerza un contradiscurso que, de modo especular, se apropia de los recursos retóricos del movimiento feminista (Gill 2017; Kuhar y Paternotte 2017; Gill y Orgad 2018; Rottenberg 2018).

El artículo parte de tres estudios de caso con el objetivo de analizar cómo se narra la misoginia popular en distintos discursos multimodales y cómo esta adquiere diferentes significados cuando la producción de sentido transita de un modo a otro y de un contexto a otro. La observación de los procesos de resemiotización de los discursos multimodales que constituyen nuestros casos de estudio nos servirá para discutir críticamente los diferentes significados asociados a las prácticas sociales que conforman la narración articulada por la misoginia popular. Finalmente nos ocuparemos de los recursos discursivos manipulativos usados para enmarcar los significados, de la «ideología de género» a la «feminazi», que se construyen resemiotizándose a partir de la ironía, la apropiación o la confrontación en función del contexto de la narración.

\section{Misoginia popular e «ideología de género»}

El impacto y las diferentes manifestaciones de reacción ante el auge del feminismo ha sido objeto de la literatura crítica feminista que se ha centrado particularmente en el auge de un movimiento de oposición al que se ha denominado misoginia popular (Banet-Weiser 2017, 2018). La presencia de la misoginia popular no puede entenderse sin el feminismo popular, o popular feminism, que de alguna manera define su circulación y estrategias discursivas (Banet-Weiser, Gill, y Rottenberg 2019). Es precisamente el término popular lo que ha sido discutido críticamente en relación tanto a la misoginia como al feminismo. Según Banet-Weiser (2017), el feminismo popular se caracteriza por una fetichización y comodificación del movimiento feminista en favor de una estrategia de confrontación. Lo «popular», en la misoginia popular, significa una aproximación frontal a las posturas antifeministas atribuyéndose una dimensión ética y de justicia social frente a las políticas feministas a las que consideran responsables de una estigmatización de los «derechos de los hombres». La retórica de la libertad de decir lo que uno quiera se lleva al extremo, ocupando un espacio antes incorporado al paradigma hegemónico del discurso misógino. La apropiación de la valentía para decir las cosas claras se observa en las manifestaciones del partido de ultraderecha Vox, 
que se refiere a la dictadura de lo políticamente correcto a la que contraponen su posición ideológica frente a los reparos discursivos de lo que llaman «la derechita cobarde» (Espartero 2019; Sanz 2019). De este modo, el relato de la misoginia popular se configura y circula en la economía de la visibilidad, esto es, en un contexto mediado que capitaliza la posibilidad de ser visto como la única forma de visibilidad (Núñez Puente y Fernández Romero 2018). El feminismo popular y la misoginia popular comparten el énfasis en la visibilidad, lo que contribuye a un proceso de especularización, o efecto de espejo deformante (Banet-Weiser 2018), en el que cada demanda del discurso feminista obtiene una respuesta de otra demanda articulada en el discurso de la misoginia popular. Es, por tanto, necesario repensar los modos en los que las narraciones de los discursos del feminismo popular y de la misoginia popular se construyen, enmarcan y circulan para indagar en las formas en las que la misoginia popular ha cooptado y transformado las propuestas del feminismo en un relato radicado en la retórica de la confrontación y la victimización.

En estos procesos de cooptación y transformación, se articula, a su vez, el concepto de «ideología de género» cuya discusión crítica contribuirá a determinar el alcance de la misoginia popular en el debate público. El surgimiento de una movilización contra las demandas del movimiento feminista se sitúa en el contexto de los avances en políticas de igualdad logrados en las Conferencias de Naciones Unidas de comienzos de los años 1990. El término «ideología de género» aparece en 2001 en un discurso del Papa Juan Pablo II (Corredor 2019, 614), refrendado por Alzamora Revoredo en el texto «Ideología de Género: sus peligros y alcances», que sustenta la «ideología de género» en «la urgencia de deconstruir los roles socialmente construidos del hombre y de la mujer» $(2004,593)$. La «ideología de género» se ha definido como una estrategia retórica orientada a refutar las demandas del movimiento feminista al tiempo que pretende esencializar y deslegitimizar la teoría de género mediante la cancelación de las políticas de igualdad (Corredor 2019, 616). En este sentido, Corredor indaga en la construcción de los marcos de sentido de la «ideología de género» como un contramovimiento epistemológico y político contra las políticas y conceptualizaciones sobre el género, el sexo y la sexualidad $(2019,617)$. Conviene tener en cuenta que enmarcar la «ideología de género» como contramovimiento permite dar cuenta de las razones tanto de la reacción antifeminista como de su circulación global $(2019,617)$. Si los movimientos sociales surgen para cambiar un determinado paradigma hegemónico mediante el cambio en la estructura de poderes, los contramovimientos, tal como advierte Corredor (2019, 617-618), emergen en el preciso momento en que los movimientos sociales capitalizan el éxito de sus demandas políticas en determinados asuntos (Mottl 1980, 620). Ello explicaría el auge de las propuestas de los partidos de ultraderecha en España precisamente cuando, tras la aprobación de la Ley Orgánica 1/2004, de 28 de diciembre, de Medidas de Protección Integral contra la Violencia de Género, el Congreso de los Diputados aprueba en diciem- 
bre de 2017 un Pacto de Estado contra la Violencia de Género, al tiempo que se presentan diferentes propuestas legislativas en defensa de los derechos LGBTQ+ (González, 2019).

Los discursos contrarios a las políticas de género se sirven, fundamentalmente, de la retórica de la «ideología de género» como contraestrategia para neutralizar al feminismo y al movimiento LGBTQ+, capitalizando así ontológicamente el concepto de género. Indagar en la interacción entre los movimientos y los contramovimientos propiciaría un mejor abordaje de las condiciones en las que estos últimos surgen y cómo su génesis puede responder a contextos de inestabilidad sociopolítica en los que determinados grupos sociales contemplan como una amenaza los avances de determinados movimientos sociales (Mottl 1980, 632). En este sentido, la literatura científica feminista se ha ocupado de examinar los modos en los que el discurso de contramovimientos como el de la misoginia popular ha fagocitado la estructura de la argumentación del discurso feminista al sugerir que son los hombres, y no las mujeres, las víctimas en la sociedad actual (Núñez Puente y Gámez Fuentes 2017; Boyle y Chamil Rathnayake 2019; Gökariksel, Neubert, y Smith 2019). Así, y una vez alcanzada la igualdad formal, el movimiento feminista habría contribuido a conformar un régimen de género en el que las mujeres demandan no la igualdad, sino propuestas totalitarias orientadas al control totalitario de los mecanismos sociopolíticos, y simbólicos, del poder (García-Favaro, y Gill 2016, 377). La «ideología de género» constituiría a este respecto el marco común a partir del que los partidos y asociaciones de ultraderecha conforman lo que se ha dado en llamar un discurso espejo que ha encontrado arraigo globalmente tanto en un determinado sistema de valores como en las estrategias políticas que los conforman (Graff, Kapur, y Walters 2019, 541).

\section{Resemiotización: construcción del significado a través del contexto}

Los procesos de resemiotización se pueden entender atendiendo a las posibilidades que ofrecen para construir diferentes discursos multimodales que cambian los significados producidos mediante un paradigma de circulación de un contexto a otro (Iedema 2001, 2003). Ello hace necesario considerar previamente la producción de discursos multimodales que suponen una transformación de sus efectos de sentido favorecida por la propia lógica de los diferentes planos semióticos en los que se articulan los discursos multimodales. La teoría de la multimodalidad permite reflexionar acerca de cómo se produce la comunicación y la interacción a través no solo un modo semiótico, sino mediante la combinación de dos o más modos. Esto incluye no solo la mirada y otras formas visuales sino también la gestualidad, la música y el sonido que, simultáneamente y en diferentes grados, construyen el significado de un discurso multimodal. Ello sin obviar que la propia interacción entre los modos es en sí misma una manera de producir sentido. 
El modo ha sido definido por Kress como un recurso socialmente modulado y dado culturalmente que produce significado $(2009,54)$. Así, los modos son las partes más pequeñas en las que se articula la producción de sentido a la que a su vez dan forma. La multimodalidad proporciona un marco a partir del que podemos desvelar los significados culturales que se adscriben a un determinado discurso, pudiendo, de esta manera, abordar los significados implícitos y las prácticas sociales vinculadas a él. Es precisamente la interacción semiótica entre los diferentes modos la que define la articulación de marcos que dan forma a los significados que configuran un discurso multimodal (Kress 2010; Kress y van Leeuwen 2006).

Los distintos modos y recursos semióticos enmarcan los significados asociados a una narración modificándose estos a través de la resemiotización. Estas modificaciones y significados incorporados mediante los modos semióticos, y enmarcados en un discurso multimodal, son especialmente relevantes en el caso de los discursos elaborados por los movimientos sociales (Cárdenas Neira 2014). Nuestro análisis explorará cómo los discursos del feminismo son enmarcados en un proceso de resemiotización por parte del discurso de la misoginia popular añadiendo modos semióticos y nuevas producciones de sentido en cada contexto hasta llegar a elaborar un discurso antagónico al de las demandas del feminismo. Según Iedema, que parte del concepto de intersemioticidad de Jakobson, la resemiotización comprende un proceso de traducción entre diferentes planos semióticos y sus respectivas materialidades (Iedema 2001, 24). Durante el proceso de resemiotización un determinado discurso, generado y enmarcado en un contexto, se transforma en otro discurso, generado y enmarcado a su vez en otro contexto. La resemiotización en su dimensión de modificación de los marcos y la producción de sentido puede contribuir a que un discurso multimodal se aparte de la interacción social que lo originó (2001, 24-25). Iedema acude al concepto de construcción social de Mehan para explicar los modos en los que las prácticas sociales se modifican de un contexto a otro, produciendo significados que se separan de la interacción social que las han creado (Iedema, 2001, 25). El concepto de «delegación» de Latour le sirve a Iedema para analizar la intersemiosis que fluctúa en el desplazamiento que se lleva a cabo desde un acto de habla a una práctica social $(2001,25)$. En nuestro caso, la «delegación» contribuye a ahondar en los procesos que hacen posible el desplazamiento, con el consiguiente cambio de significado, del discurso del feminismo a cómo este es enmarcado por el discurso de la misoginia popular. Así indagaremos en cómo los significados se modifican a través de los modos semióticos gracias a la resemiotización y cómo se producen desplazamientos e, incluso, la separación del sentido original del discurso. Ello contribuirá a reflexionar sobre cómo la inteligibilidad de los discursos no depende tanto de sus propias condiciones de veracidad, sino de las condiciones de su construcción (Kofman 2018). 


\section{Discurso y manipulación: estrategias discursivas para ejercer el control}

En su estudio sobre la manipulación, van Dijk (2006) la define como una práctica comunicativa e interaccional en la cual el manipulador ejerce control sobre otras personas, generalmente en contra de su voluntad o de sus intereses. El autor distingue tres dimensiones de la manipulación. Por un lado, la social, que implica abuso de poder por élites simbólicas que tienen acceso preferencial al discurso público y manipulan a grupos de personas a favor de sus propios intereses y en contra del interés de las víctimas. Por otro lado, la dimensión cognitiva, que explica cómo el procesamiento del discurso y la formación de modelos mentales y representaciones sociales son controlados por el discurso manipulativo. Por último, la dimensión discursiva, que hace referencia a las propiedades del discurso que se utilizan para manipular las mentes de los receptores.

Según van Dijk, la manipulación implica dominación, ejercicio de influencia ilegítima por medio del discurso. Muchas de las formas contemporáneas de manipulación comunicativa son multimodales. En ellas, a los receptores se les asigna un papel pasivo, son víctimas de la manipulación, entendida como un fenómeno discursivo-semiótico. Van Dijk detecta que, para estar en condiciones de manipular a muchos otros a través del texto oral o escrito, es preciso tener acceso a alguna forma de discurso público: «la manipulación es una de las prácticas discursivas de los grupos dominantes dirigidas hacia la reproducción de su poder» (2006).

De acuerdo con van Dijk, el significado manipulativo (o evaluación crítica) del texto oral o escrito depende de los modelos contextuales de los receptores, incluyendo sus modelos de los hablantes o escritores y las intenciones que se les atribuye. «El discurso se define como manipulativo, en primer lugar, en términos de los modelos contextuales de los participantes» (2006) Esta característica del discurso manipulador es esencial para nuestro análisis, dado que, como indica van Dijk, se define en función de las categorías vinculadas al contexto; y es en estos cambios de contexto cuando se produce la resemiotización.

Las estrategias discursivas para ejercer la dominación pasan, según el autor, por enfatizar la posición propia, el poder, la autoridad o la superioridad moral del hablante o de sus fuentes y la posición inferior y la falta de conocimiento de los receptores. Asimismo, es posible enfocar las creencias que el manipulador quiere que el receptor acepte como conocimiento, así como los argumentos y pruebas que hacen que esas creencias sean más aceptables. Otras de las estrategias se basan en la desacreditación de las fuentes o las creencias alternativas (disidentes); o en la apelación a las ideologías, las actitudes y las emociones relevantes de los receptores.

Algunas de las categorías que establece van Dijk para analizar los discursos manipulativos nos van a resultar útiles en nuestra indagación en tres casos de estudio sobre las estrategias de construcción discursiva de la misoginia popular como contramovimiento. Estas son las siguientes: 
- Generalización. Consiste en utilizar un ejemplo concreto específico que ha impactado en los modelos mentales de la gente para generalizarlo a conocimiento y actitudes o, incluso, a ideologías fundamentales.

- Polarización. Se construye entre el Nosotros (buenos e inocentes) y Ellos (malos y culpables).

- Autopresentación positiva, por superioridad moral y enfatizando el propio poder; presentación negativa de los otros, descrédito al oponente, dando detalles de los «hechos».

- Macroactos de habla que implican Nuestras «buenas» obras y sus «malos» actos, por ejemplo, acusación, defensa.

- Actos de habla locales que implementan y apoyan los globales, esto es, afirmaciones que prueban las acusaciones.

- Reiteración del mensaje y explotación de sucesos relacionados.

- Conocimiento parcial, mal dirigido o prejuiciado frente al conocimiento generalmente relevante y potencialmente crítico.

- Apelación a las emociones mediante palabras emotivas especiales o el uso de la retórica dramática (hipérboles), de creencias apasionadas.

- Culpar a la víctima. Es una de las formas en las que el grupo dominante discursivamente influencia los modelos mentales de los receptores, por ejemplo, mediante la reatribución de la responsabilidad de las acciones a favor de sus propios intereses.

- Uso de figuras retóricas: hipérboles vs. eufemismos para significados positivos/negativos; metonimias y metáforas que enfatizan nuestras/sus propiedades positivas/negativas.

A estas categorías podríamos sumar otras sobre las que también nos interesa reflexionar en los casos de estudio propuestos, como son:

- La lexicalización: entendida como la incorporación de un significado de origen figurado o metafórico al léxico general de una lengua.

- Uso del humor, la ironía, la sátira. En su estudio sobre el discurso racista, Pérez (2013) analiza cómo los cómicos logran hacerlo aceptable utilizando ciertas estrategias que rodean las constricciones del discurso racial público. Tanto el humor como la ironía, indica Pérez, permiten reducir la responsabilidad personal sobre el discurso, creando distancia entre el autor y lo que dice. Esto se logra a través de la metáfora de la línea roja entre lo que es agradable y ofensivo; la autorrepresentación positiva y la representación negativa de los «Otros» o la creación de distancia y la denegación del discurso racista en abierto.

- Dinámica de la apropiación-cooptación que resulta en una inversión del discurso. Esto permite construir una narración especular para ensalzar los logros propios y anular/eliminar los del oponente. 
- Distribución y circulación masiva de los discursos y sus consecuencias. Esta circulación permite, en ocasiones, la apropiación de categorías ajenas y favorece la visibilidad y popularización del discurso propio.

\section{Casos de estudio}

En las líneas que siguen, nos detendremos en el análisis de tres casos de estudio que corresponden a tres narraciones multimodales para investigar cómo se articulan en ellos los mecanismos de construcción discursiva de la misoginia popular como contramovimiento.

\subsection{Ironía y misoginia: cuando las «feminazis» visitan Vox}

El partido ultraderechista Vox publicó un vídeo en sus redes sociales en el que tildaba de «feminazis» y ridículas a un grupo de mujeres que acudieron a su sede a protestar el 8 de marzo de 2019. La pieza comienza con el rótulo "Así visitan las feminazis la sede de VOX...» al que acompañan algunas imágenes de las activistas frente a la sede del partido coreando consignas contra el machismo. A continuación, se introduce música de fondo de la serie cómica El Show de Benny Hill y se aceleran los fotogramas en los que las activistas juegan con la colocación de un cartel en el que quitan y ponen la letra «X» entre la «O» y la «l» de la palabra «bolleras». También se las escucha corear «España mañana será lesbiana» a la par que colocan banderas republicanas encima de las imágenes de la bandera roji-

\section{Figura 1.}

Tuit «Gracias por vuestra loca visita»

Fuente: Cuenta de Twitter de Vox

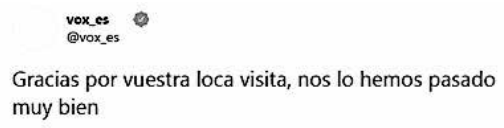

\#HuelgaFeminista2019 \#InternationalWomensDay \#8Marzo \#FelizDiaDeLaMujer

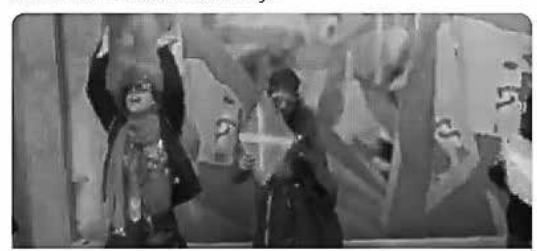

378.5 mil visualizaçues $\quad 0.04 / 0.29$

Asi visitan las feminazis la sede de VoX...

1:34 PM - 8 de mar de 2019 - Twitter Ads 
gualda. Un rótulo en el que se contrapone el trabajo por España que realiza el partido a la innecesaria, y ridícula, protesta del grupo de feministas sirve de final del vídeo: «Mientras que vosotros hacéis el ridículo nosotros seguimos trabajando por España.» Vox abre su publicación de Twitter con la irónica frase «Gracias por vuestra loca visita, nos lo hemos pasado muy bien» acompañada de un emoji guiñando el ojo y sacando la lengua. Para la publicación del vídeo se usaron los hashtags del 8M \#HuelgaFeminista2019, \#InternationalWomensDay, \#8Marzo y \#FelizDiaDeLaMujer junto a una imagen que da acceso al vídeo.

Tanto el texto como el vídeo que Vox sube a Twitter constituyen un discurso multimodal orientado no solo a ignorar las demandas de las feministas en la jornada del 8M, sino también a reforzar un proceso de inversión en el que sirviéndose de recursos retóricos como la ironía se deslegitima discursivamente el movimiento feminista (Malmqvist 2015). En este caso, el recurso al humor y a la ironía sirven al partido ultraderechista para reducir su responsabilidad con respecto al discurso en el que se acusa de «feminazis» y ridículas a quienes participan de la protesta. Vox se separa de las denuncias y las banaliza utilizando la sátira por medio de la música y la aceleración de las imágenes que conectan con sistemas de sentido asociados a la parodia más vulgar.

\section{Figura 2.}

«Así visitan las feminazis la sede de VOX... \#8M»

Fuente: Canal de YouTube de Vox

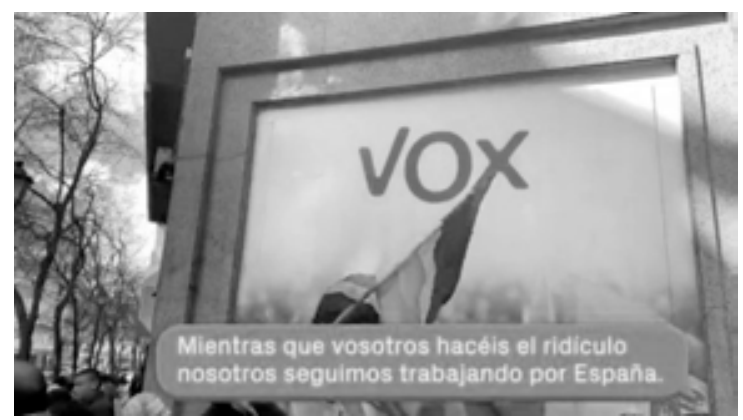

Siguiendo a Pérez (2013), el humor trata de convertir en no ofensivas ciertas calumnias que en otro contexto hubieran resultado graves. Sin embargo, la ironía y la sátira conducen a una interpretación jocosa y hasta divertida que desplaza el contexto y resemiotiza una protesta indignada en una «loca visita». La autorrepresentación positiva en un relato polarizado eclosiona en este marco sobre todo a través de la frase en la que Vox se asigna la cualidad de partido que trabaja por España. Así se postula frente a la representación negativa de «los Otros», «las feminazis» que protagonizan la «ridícula» protesta inferida como inútil a la par que cómica. 
Vox incide en que la «loca visita» les ha permitido pasarlo «muy bien», llegar a disfrutar. De este modo, junto con la apropiación de las etiquetas de la protesta del 8 de marzo, son capaces de acrecentar la distancia y denegar un explícito discurso machista en la esfera pública. El discurso multimodal generaliza deslegitimando y descalificando un discurso de protesta y elevando a la categoría de conocimiento e ideología fundamental el de aquéllos que trabajan por España mientras otras pierden el tiempo. La dinámica apropiación-cooptación ensalza por tanto los logros propios y anula/elimina los del oponente en una narración especular que devuelve a las activistas una imagen excéntrica y trastornada de sus acciones.

La distribución y circulación masiva de estos discursos a través de las redes sociales favorece que el discurso sea visible. Vox consigue así popularizar el mensaje que traza el imaginario de partido serio pero capaz de burlarse de quienes invierten su tiempo en intervenciones divertidas por perturbadas. El tránsito, y desplazamiento posterior, de la producción de significado de un discurso multimodal, la protesta feminista frente a la sede de Vox, a otro, el discurso multimodal que Vox articula de manera especularizante, muestran cómo la misógina popular se sirve de la resemiotización para construir su propia narración sobre el feminismo y sus demandas políticas.

\subsection{De Rosie, la Remachadora a la misoginia popular}

El 6 de enero de 2019, el periódico El Mundo (Negre 2019) publicó una entrevista con la líder por Madrid del partido ultraderechista Vox, Rocío Monasterio. Bajo el titular «Rocío Monasterio: La musa de Vox contra las 'feminazis'», la aban-

Figura 3.

La diputada de Vox en la asamblea de Madrid, Rocío Monasterio, imita la pose de «Rosie, la Remachadora».

Fuente: El Mundo, 6 de enero de 2019.

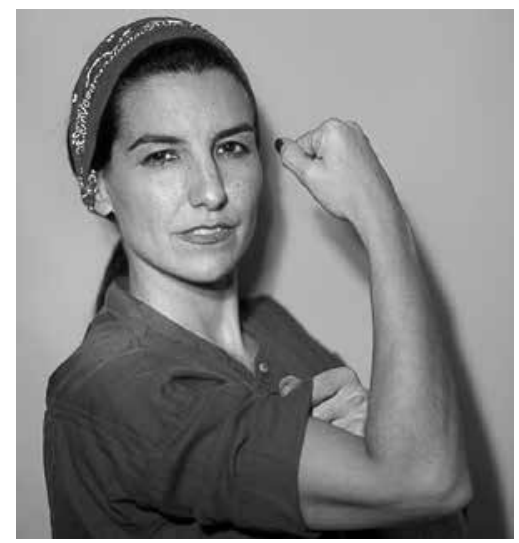


derada de la lucha contra el «negocio de la ideología de género» posaba en una fotografía a gran tamaño ataviada como Rosie, la Remachadora a iniciativa del diario. En la respuesta a las cuestiones, la líder política recurre a estrategias discursivas que ahondan en las que utiliza su partido y que implican una clara tendencia a la manipulación. Con esta entrevista, la líder contribuye a la distribución masiva del discurso de Vox frente a la «ideología de género» apropiándose de categorías ajenas, como lo es un icono tan representativo del feminismo, y favoreciendo su visibilidad con un relato populista claramente polarizado.

Uno de los mecanismos manipulativos que detecta van Dijk y que emplea Rocío Monasterio como portavoz de la ideología de su partido es la generalización. Su defensa a ultranza de una ley de violencia intrafamiliar, frente a la Ley Integral contra la violencia de género, para proteger «tanto a las mujeres como a niños o señores mayores» es la máxima que la líder pretende generalizar durante toda la entrevista a modo de conocimiento e ideología fundamental para impactar en los modelos mentales de la sociedad. Como adalid de esta ideología, Monasterio polariza la narrativa entre su figura como Rosie «la (auténtica) feminista», actante que entra en litigio en el discurso contra «Ellas», representantes del «feminismo supremacista que impone el discurso de la ideología de género». En su afán por ahondar en la autopresentación positiva, la política se dota de superioridad moral y enfatiza su poder a través de la utilización de referentes como Concepción Arenal (colgada de un cuadro en su despacho) y se declara feminista desde que tiene «uso de razón». «Ellas», «las Otras», son desacreditadas y acusadas de «amordazarnos con su burka ideológico».

Con apoyo del periodista, que dibuja desde el inicio a una líder poderosa pero amenazada y escracheada en redes y en las manifestaciones del 8 de marzo por defender sus ideas, Monasterio ensalza sus «buenas» obras y las de su partido en la defensa de «los niños» o «los señores mayores» «que también pueden ser víctimas». Los «malos» actos se atribuyen en el relato a quienes quieren imponer «la dictadura del feminismo». Esta acusación se prueba y se eleva a categoría de «global» por medio de ejemplos reiterados y de contundentes afirmaciones que tratan de combatir «ese hembrismo que ahora critica a los jueces porque quiere entrar en la Justicia para captar más subvenciones». De este modo, se conduce a los lectores a adquirir un conocimiento parcial y prejuiciado en un discurso polarizado, insistiendo en el argumentario de que es necesario «fiscalizar» las ayudas a los colectivos feministas «que se han montado chiringuitos que hace que el dinero no llegue a quien necesite».

Rocío Monasterio culpa así a la víctima, acusando a ciertos grupos de mujeres maltratadas de velar por sus intereses frente al resto. Y coopta y se apropia de su lugar, invirtiendo el discurso y construyendo una narración especular que ubica a las «víctimas masculinas» como las verdaderas damnificadas de un sistema injusto que no vela por ellas, que las margina. Para ello, recurre a la apelación a las emociones y a las creencias apasionadas mostrando su indignación ante 
lo que considera una injusticia. La retórica dramática se inscribe en declaraciones que exigen la derogación de una norma «que no respeta la presunción de inocencia»: «no puede ser que la ley trate distinto a los españoles según su sexo, va en contra de la Constitución». De este modo, se anulan y se invisibilizan los logros del «oponente», como son la defensa y aprobación en su momento de una ley integral o las reiteradas cuestiones de inconstitucionalidad que el Tribunal Constitucional siempre ha fallado en contra.

A pesar de lo polarizado de su discurso, Monasterio se desmarca de la lexicalización de la que hace gala su partido declarando que a esas «Otras» no le gusta tildarlas de «feminazis» «para no mezclarlo con el nazismo». Sin embargo, como dijimos, no tiene reparos en hablar de la «dictadura del feminismo» o del «burka ideológico» a modo de hipérboles para ensalzar la mordaza de ese otro feminismo al que alía con un Estado que en su opinión trata a las mujeres «como débiles». Enfundada en su camisa azul y con el pañuelo rojo, satiriza e ironiza con ese icono para representar a las mujeres que logran las cosas «por méritos propios» frente aquellas a las que se lo dan hecho. Colocada al inicio de la pieza junto al contundente titular, imagen y texto ahondan en la idea de que defender que la violencia no tiene género no implica ser machista: «Si fuera Vox machista yo no estaría aquí ni muchas mujeres que nos apoyan porque no quieren sentirse humilladas con políticas de cuotas o que nos lleven a una tele por ser una mujer.»

Por medio de estos mecanismos, su discurso logra resemiotizar varios símbolos feministas. Rosie, la Remachadora se desprende de sus sistemas de sentido y se adscribe a un feminismo que hace justicia con todas las víctimas: mujeres, niños, hombres, mayores. Igualmente, la violencia que afecta a todos los estratos se desprende de su carácter «de género» y con ello deslegitima una ley que nace con la base de una discriminación positiva y que se desdibuja en una justicia igual para los sexos.

\subsection{Feminazis y violencia de género}

La asociación ultraconservadora Hazte Oír fletó un autobús en febrero y marzo de 2019 contra el «feminismo radical» con el fin de solicitar explícitamente a los líderes de los partidos conservadores PP, Ciudadanos y Vox la derogación de las leyes de género y contra la violencia machista (Europa Press 2019). Hasta el 8 de marzo, jornada de huelga feminista, el autobús circuló por varias ciudades españolas para frenar la Ley Integral contra la Violencia de Género de 2004 y las normas de apoyo y respeto a la comunidad LGTBI promovidas por algunas comunidades autónomas. «No es violencia de género, es violencia doméstica» fue el eslogan principal de esta protesta móvil que además quería incidir en que «Las leyes de Género discriminan al hombre». El autobús incluía a su vez un busto del 


\section{Figura 4.}

Imagen del autobús fletado por Hazte Oír para denunciar la «ideología de género», «las feminazis» y la Ley contra la violencia de género de 2004.

Fuente: El País, 28 de febrero de 2019.

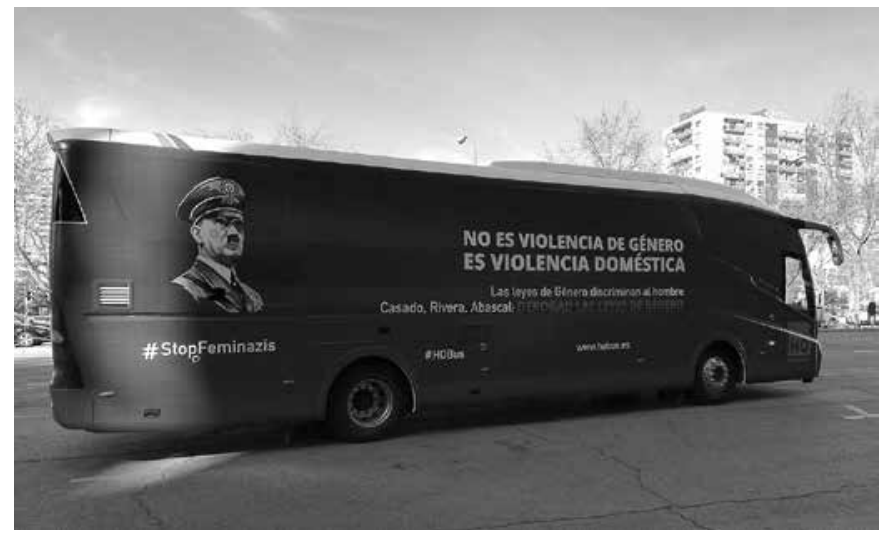

dictador nazi Adolf Hitler con el rostro maquillado y el símbolo feminista en la gorra. Debajo de esta figura se inscribía el hashtag StopFeminazis.

En estos discursos multimodales observamos algunos de los mecanismos retóricos manipulativos que también estaban presentes en otras manifestaciones discursivas del partido ultraderechista Vox, íntimo aliado de la asociación Hazte Oír. De nuevo, el eslogan principal apela a una generalización que pretende impactar en la población difundiendo una ideología confrontada con otra, «la de Género». El discurso polarizado permea los mensajes, señalando, por un lado, a los defensores de «todas» las víctimas de violencia que están implícitas en la categoría de «doméstica». Por otro lado, se acusa a quienes apoyan «las leyes de Género», dado que éstas son discriminatorias con el hombre y favorecen solo a la mujer.

En esa autorrepresentación positiva, se enfatizan el poder y la superioridad moral de quienes defienden a las víctimas de la discriminación, los hombres, y se desacredita a aquellas que imponen la «dictadura» de la ideología de género, las «feminazis». A ellas se alude a través de la imagen de Hitler, caricaturizado con símbolos feministas, y a través del acto de habla de la etiqueta StopFeminazis, en la que se explicita la conexión entre el nazismo y las feministas. De este modo, el concepto se lexicaliza y también se resemiotiza, al modificarse su sentido por cambiar de contexto. Como refuerzo, la apelación imperativa a los tres líderes políticos para que «deroguen las leyes de Género» apoya la ideología global, reitera el mensaje y fomenta el conocimiento parcial, mal dirigido y prejuiciado frente al conocimiento generalmente relevante y potencialmente crítico al que se apela y denosta a través de la ridiculización.

Las víctimas de violencia de género son sustituidas e invisibilizadas en pro de las víctimas de violencia doméstica. No solo eso: se las culpa de velar por sus 
propios intereses por medio del insulto. En esta dinámica de la apropiación-cooptación que resulta en una inversión del discurso sobre la víctima, se construye una narración especular que ensalza los logros propios, de quienes apuestan por todas las víctimas; y anula/elimina los del oponente: quienes quieren apropiarse de los recursos a través de «las leyes de Género».

El autobús trata de mover emociones a partir de la apelación directa a los líderes políticos por medio de sus apellidos para que tomen cartas en el asunto y se impliquen en la transformación del statu quo. La sátira de la imagen amplía la distancia con respecto al discurso acusador que a través del humor trata no de cruzar la línea roja entre lo agradable y lo ofensivo, que sin embargo sí se trasgrede por medio de la etiqueta StopFeminazis.

La circulación masiva de los discursos, en este caso a través de un soporte móvil como es el autobús, promueve una visibilidad que resulta incómoda y avasalladora. A su vez, este modo de difusión es capaz de popularizar un relato que se resemiotiza por inmiscuirse en el espacio público de forma legítima, lo cual da un sentido más poderoso y más impune al insulto a las feministas en un relato claramente polarizador que las vincula con una ideología fascista frente a los «buenos» defensores de las víctimas de violencia doméstica.

\section{Conclusiones}

El análisis de los tres casos de estudio propuestos muestra los modos en los que la misoginia popular construye un relato multimodal, al que se incorporan diferentes producciones de sentido. Ello permite que, mediante la resemiotización por medio de la manipulación, al relato sobre el feminismo se adscriban significados y prácticas sociales alejadas de las demandas políticas del movimiento feminista, siendo estas enmarcadas por la narración que la misoginia popular articula de la «ideología de género».

En nuestro estudio nos hemos servido del concepto de resemiotización y de las categorías que establece van Dijk para analizar los discursos manipulativos sobre el feminismo que la misoginia popular construye. Mediante estas dos aproximaciones metodológicas hemos abordado tres casos de estudio sobre las estrategias de construcción discursiva de la misoginia popular como contramovimiento en España.

De este modo, hemos observado cómo emerge un contradiscurso especular que se apropia y resignifica los recursos retóricos del movimiento feminista. Así, mediante la difusión de un vídeo a través de sus redes sociales, Vox convierte en «loca» $\mathrm{y}$ «ridícula» una protesta feminista frente a su sede mientras se erige como el partido serio que trabaja por España. También desplaza el sentido original del símbolo de Rosie, la Remachadora y lo utiliza como icono feminista de quienes luchan contra las «feminazis» encarnado en la líder del partido ultraconservador. 
A través de la circulación de un autobús con la imagen caricaturizada de Hitler asociada al feminismo, Hazte Oír polariza el discurso entre quienes defienden la «violencia de género», adalides de las injustas «leyes de Género», frente a quienes apuestan por la «violencia doméstica» que es capaz de proteger a «todas las víctimas».

Con ello, la misoginia popular se construye como un contramovimiento que se atribuye la dimensión ética y de justicia social del feminismo, cuya estructura argumentativa es fagocitada al remarcar que son los hombres y no las mujeres las víctimas en la sociedad actual. Como parte de su contraestrategia, la misoginia popular acusa a las «feminazis» de apoyar posturas orientadas al control totalitario de los mecanismos sociopolíticos y simbólicos del poder. A partir de la ironía, la sátira, la apropiación y la confrontación, promueve un discurso espejo que es capaz de arraigar en sistemas de valores y en estrategias políticas que la conforman.

La circulación cultural de la misoginia popular permite su visibilidad y el reposicionamiento y la recategorización por medio de recursos multimodales y manipulativos que derivan en una resemiotización que añade nuevas formas de producción de sentido en diferentes contextos para elaborar un discurso antagónico al del feminismo.

Estas formas de visibilidad, que también son propias del feminismo, logran que la misoginia popular como contramovimiento aparte el discurso feminista de la interacción social que lo originó y actúe a modo de espejo deformante a través de la retórica de la confrontación y la victimización que se configuran, por generalización y polarización, como elementos legitimadores del discurso misógino popular.

\section{Referencias bibliográficas}

Alzamora Revoredo, Óscar. 2004. «Ideología de Género: sus peligros y alcances.» En Consejo Pontificio para la Familia. Lexicón. Términos ambiguos y discutidos sobre familia, vida y cuestiones éticas, 593-608. Madrid: Ediciones Palabra.

Banet-Weiser, Sarah. 2017. «Popular Misogyny: A Zeitgeist.» Culture Digitally. Disponible en: https://culturedigitally.org/2015/01/popular-misogyny-azeitgeist/[Consulta en 12 de noviembre de 2019].

Banet-Weiser, Sarah. 2018. Empowered: Popular Feminism and Popular Misogyny. Durham, NC: Duke University Press.

Banet-Weiser, Sarah, Rosalind Gill, y Catherine Rottenberg. 2019. «Postfeminism, popular feminism and neoliberal feminism? Sarah Banet-Weiser, Rosalind Gill and Catherine Rottenberg in conversation.» Feminist Theory 21 (1): 3-24. DOI: https://doi.org/10.1177 /1464700119842555

Boyle, Karen, y Chamil Rathnayake. 2019. «\#HimToo and the networking of misogyny in the age of \#MeToo.» Feminist Media Studies. DOI: https://doi.org/10.1080/14680777.2 019.1661868 
Cárdenas Neira, Camila. 2014. «Representación visual de la movilización estudiantil en Chile: las fotografías de las marchas como espacios de narración, actuación e identificación política.» Onomázein IX: 115-137. DOI: https://doi.org/10.7764/onomazein.alsfal.11

Corredor, Elizabet S. 2019. «Unpacking 'Gender Ideology' and the Global Right's Antigender Countermovement.» Signs: Journal of Women in Culture and Society 44 (3): 613-638. DOI: https://doi.org/10.1086/701171

Espartero, Marta. 2019. «Rocío Monasterio, látigo de Vox: ‘El PP es la derechita cobarde, una marca vieja caduca como Kodak'.» El Español, 19 de enero de 2019. Disponible en: https://www.elespanol.com/opinion/20190113/rocio-monasterio-vox-pp-derechita-caducado-kodak/367963631_0.html [Consulta en 15 de noviembre de 2019].

Europa Press. 2019. «Hazte Oír usa la imagen de Hitler en un autobús para caricaturizar las leyes contra la violencia machista.» El País, 28 de febrero de 2019. Disponible en: https://elpais.com/sociedad/2019/02/28/actualidad/1551358015_148714.html [Consulta en 12 de noviembre de 2019].

García-Favaro, Laura, y Rosalind Gill. 2016. «'Emasculation nation has arrived': sexism rearticulated in online responses to Lose the Lads' Mags campaign.» Feminist Media Studies 16 (3): 379-397. DOI: https://doi.org/10.1080/14680777.2015.1105840

Gill, Rosalind. 2017. «The Affective, Cultural and Psychic Life of Postfeminism.» European Journal of Cultural Studies 20 (6): 606-626. DOI: https://doi.org/10.1177/136754 9417733003

Gill, Rosalind, y Shani Orgad. 2018. «The Amazing Bounce-backable Woman: Resilience and the Psychological Turn in Neoliberalism.» Sociological Research Online 23 (2): 477 495. DOI: https://doi.org/10.1177/1360780418769673

Gökarıksel, Banu, Christopher Neubert, y Sara Smith. 2019. «Demographic Fever Dreams: Fragile Masculinity and Population Politics in the Rise of the Global Right.» Signs: Journal of Women in Culture and Society 44 (3): 561-587. DOI: https://doi.org/ $10.1086 / 701154$

González, Miguel. 2019. «El Congreso blindará los derechos de las personas LGTBI con una ley estatal.»El País, 27 de junio de 2019. Disponible en: https://elpais.com/politica/2019/06/26/actualidad/1561565785_705434.html [Consulta en 19 de noviembre de 2019].

Graff, Agnieszka, Ratna Kapur, y Suzanna Danuta Walters. 2019. «Gender and the Rise of the Global Right.» Signs: Journal of Women in Culture and Society 44 (3): 541-560. DOI: https://doi.org/10.1086/701152

Iedema, Rick. 2001. «Resemiotization.» Semiotica 137 (1/4): 23-39. DOI: https://doi.org/ 10.1515/semi.2001.106

Iedema, Rick. 2003. «Multimodality, Resemiotization: Extending the Analysis of Discourse as Multi-semiotic Practice.» Visual Communication 2 (1): 29-57. DOI: https://doi. org $/ 10.1177 / 1470357203002001751$

Kofman, Ava. 2018. «Bruno Latour, the Post-Truth Philosopher, Mounts a Defense of Science.» The New York Times. Disponible en: https://www.nytimes.com/2018/10/25/ magazine/bruno-latour-post-truth-philosopher-science.html [Consulta en 13 de noviembre de 2019].

Kress, Gunter. 2009. «What is mode?» En The Routledge handbook of multimodal analysis, editado por C. Jewett, 54-67. New York: Routledge.

Kress, Gunther. 2010. Multimodality: A Social Semiotic Approach to Contemporary Communication. London y New York: Routledge. 
Kress, Gunther, y Theo van Leeuwen. 2006. Reading images. The Grammar of Visual Design. New York: Routledge.

Kuhar, Roman, y David Paternotte, eds. 2017. Anti-gender campaigns in Europe: Mobilizing against equality. Lanham, MD: Rowman \& Littlefield.

Malmqvist, Karl. 2015. "Satire, racist humour and the power of (un)laughter: On the restrained nature of Swedish online racist discourse targeting EU-migrants begging for money." Discourse E Society 26 (6): 733-753. DOI: https://doi.org/10.1177/095792 6515611792

Mottl, Tahi L. 1980. «The Analysis of Countermovements.» Social Problems 27 (5): 620-635. DOI: https://doi.org/10.1525/sp.1980.27.5.03a00090

Negre, Javier. 2019. «Rocío Monasterio. La musa de Vox contra las 'feminazis'.» El Mundo, 6 de enero de 2019. Disponible en: https://www.elmundo.es/cronica/2019/01/06/5c2f9122fdddffd09b8b469a.html [Consulta en 12 de noviembre de 2019].

Núñez Puente, Sonia, y María José Gámez Fuentes. 2017. «Spanish feminism, popular misogyny and the place of the victim.» Feminist Media Studies 17 (5): 902-906. DOI: https:// doi.org/10.1080/14680777.2017.1350527

Núñez Puente, Sonia, y Diana Fernández Romero. 2018. «Discurso visual posmachista en Twitter: análisis multimodal de la iconicidad de la victimización.» Dígitos 4: 131-148. Disponible en: https://revistadigitos.com/index.php/digitos/article/view/127.

Pérez, Raúl. 2013. «Learning to make racism funny in the 'color-blind' era: Stand-up comedy students, performance strategies, and the (re)production of racist jokes in public.» Discourse $\mathcal{E}$ Society 24 (4): 478-503. DOI: https://doi.org/10.1177/0957926513482066

Rottenberg, Catherine. 2018. The Rise of Neoliberal Feminism. New York: Oxford University Press.

Sanz, Marta. 2019. «Diminutiva». El País, 13 de mayo de 2019. Disponible en: https://elpais. com/elpais/2019/05/12/opinion/1557671711_751131.html [Consulta en 15 de noviembre de 2019].

van Dijk, Teun. 2006. «Discurso y manipulación: Discusión teórica y algunas aplicaciones.» Revista Signos 39 (60): 49-79. DOI: https://doi.org/10.4067/S0718-09342006000100003

Sonia Núñez Puente. Profesora Titular en la Universidad Rey Juan Carlos (Madrid). Ha dirigido diferentes proyectos de investigación sobre violencia de género y prácticas digitales. Asimismo, ha publicado extensamente en el área de los Estudios de Género y Comunicación.

Correo electrónico: sonia.puente@urjc.es

Diana Fernández-Romero. Docente e Investigadora en la Universidad Rey Juan Carlos (Madrid). Ha publicado en revistas de alto impacto sobre Estudios de Género y Comunicación y ha liderado y participado en proyectos de investigación sobre el área. Correo electrónico: diana.fernandez.romero@urjc.es

Artículo recibido en 29 de diciembre y aceptado para publicación en 13 de abril de 2020. 